\title{
DIFFERENCES IN METABOLISM OF REICHSTEIN'S SUBSTANCE S IN NORMAL ADULTS AND CHILDREN ${ }^{1}$
}

\author{
By ALFRED M. BONGIOVANNI, WALTER R. EBERLEIN, AND JOAN L. CADDELL \\ WITH THE TECHNICAL ASSISTANCE OF WILLFRIED EDER
}

\author{
(From the Endocrine Division, Children's Hospital of Philadelphia, and the Department of \\ Pediatrics, University of Pennsylvania, Philadelphia, Pa.)
}

(Submitted for publication February 12, 1958; accepted March 20, 1958)

The excretion of "corticoids" in the urine of human subjects remains relatively constant throughout life, when referred to body surface area. The excretion of 17 -ketosteroids in the urine, however, progressivly rises during adolescence (1).

In the adolescent male, increased 17-ketosteroid excretion is in part attributable to developing testicular function. It is believed that in both sexes increased adrenocortical secretion at puberty is also responsible, although the exact nature of the alteration which occurs is unknown. Talbot, Zygmuntowicz, Wood, and Christo have suggested that a "second" adrenocorticotropic hormone, specifically responsible for the stimulation of 17 ketosteroid production, appears during this era of human life (1).

The increased pubertal excretion of 17 -ketosteroids derived from the adrenal cortex may also reflect altered extra-adrenal metabolism of steroids. Certain of the C-21 adrenocortical steroids are known to be degraded to 17 -ketosteroids in the body. The greater quantities of urinary $17-$ ketosteroids appearing with the attainment of maturity might then arise from increased conversion of C-21 steroids to such metabolites. In order to test this hypothesis, $\Delta^{4}$-pregnene-17 $\alpha, 21$ diol,3,20-dione (hereafter designated as Substance S) was administered by various routes to children and adults, and the excretion of 17-ketosteroids and other metabolites was measured. One of the major urinary metabolites of this compound is the 17-ketosteroid, etiocholanolone (2).

1 This work was made possible by a grant (No. P-5) from the American Cancer Society, Inc., and the Division of Research Grants and Fellowships of the National Institutes of Health [A-619 (C3)], United States Public Health Service.

\section{METHODS}

The subjects were healthy adult volunteers and children from the wards of the Children's Hospital of Philadelphia. The children were convalescent from brief, acute minor illnesses and were well at the time of the study. A 24 hour collection of urine was obtained before and after the administration of Substance S. The urine was collected under a small volume of toluene and stored at $6^{\circ} \mathrm{C}$. All urines were examined within one week of collection.

For the measurement of 17 -ketosteroids, two $10 \mathrm{ml}$. aliquots of urine were hydrolyzed, one with 12 per cent (v/v) sulfuric acid (added as 40 per cent sulfuric acid) at $80^{\circ} \mathrm{C}$. for 10 minutes, and the other with beta glucuronidase $^{2}$ (beef liver), 250 units per $\mathrm{ml}$. for 48 hours at $37^{\circ} \mathrm{C}$. Each was extracted with ether and washed (3). The Zimmermann reaction was performed on a small fraction, equivalent to $1.0 \mathrm{ml}$. of urine, according to the technique previously described (4), modified after Wilson (5). Total urinary corticoids were measured by the method of Silber and Porter (6), with the use of suitably smaller aliquots when the levels were extremely high. Pregnanetriol (pregnane-3 $\alpha, 17 \alpha, 21$-triol) was estimated by the method of Bongiovanni and Eberlein (7).

The formaldehydogenic steroids were determined as follows: Ten ml. aliquots of urine were hydrolyzed with beta-glucuronidase ( 500 units per $\mathrm{ml}$, at $\mathrm{pH} 4.5,37^{\circ} \mathrm{C}$., for 48 hours) and extracted three times with equal volumes of ethyl acetate. The combined extract was washed twice with one-twelfth volume of $0.1 \mathrm{~N} \mathrm{NaOH}$, and twice with one-twelfth volume of water. All washes were re-extracted with ethyl acetate. After evaporation of the ethyl acetate, the residue was treated with Girard's reagent $T$ in the manner of Schneider (8) and only the nonketonic portion was investigated. The nonketonic residue was partially purified by application to a silica gel column $(0.8 \times 3.0 \mathrm{~cm}$. $)$ in 2 per cent ethanol $/$ methylene chloride. After washing the column with $10 \mathrm{ml}$. each of 2 per cent ethanol and 3 per cent ethanol/methylene chloride, the eluate after the application of $25 \mathrm{ml}$. 10 per cent ethanol/methylene chloride was collected and evaporated at $40^{\circ} \mathrm{C}$. with an air current. Suitable aliquots of this fraction were examined by periodate oxidation for nonketonic formaldehydogenic steroids (9).

In one experiment, detailed below, the pooled urine from two subjects was hydrolyzed with beta-glucuronidase, ex-

\footnotetext{
2 Ketodase ${ }^{\circledR}$, Warner-Chilcott.
} 
tracted three times with one-third volume of ethyl acetate by hand, and washed in the manner described for the smaller aliquots. The extract was chromatographed on silica gel (10). Another pool of urine, specified below, was similarly hydrolyzed, extracted and resolved by chromatography on alumina (11). Both chromatograms were carried to completion within 24 hours.

Substance $\mathrm{S}$ was administered in two forms: as the hemisuccinate, by mouth and intravenously; and as the acetate, by mouth only. The single dose of hemisuccinate administered orally was 4.5 to $5.5 \mathrm{mg}$. per $\mathrm{Kg}$. (expressed as weight of the free steroid), given at the beginning of the second 24 hour collection of urine. In all other instances, the amount of the steroid, as the hemisuccinate by vein or the acetate by mouth, was 1.0 to $1.5 \mathrm{mg}$. per $\mathrm{Kg}$., administered as a single dose. The hemisuccinate and acetate were prepared by standard procedures (12). In three adult subjects, the acetate of $\Delta^{4}$-pregnene$11 \beta, 17 \alpha, 21$-triol-3,20-dione (hereafter designated "hydrocortisone") was administered orally for purposes of comparison.

\section{RESULTS}

The urinary excretion of 17 -ketosteroids (after glucuronidase hydrolysis alone), corticoids, and formaldehydogenic steroids, before and after the administration of Substance $S$, is shown in Table I. Certain subjects were used repetitively. The formaldehydogenic steroids were determined only after the use of the acetate of Substance S. The quantities of pregnane-3 $\alpha, 17 \alpha, 21$-triol excreted were within normal limits for all subjects $(7)$ and did not change. In Table II, the results are expressed as the percentage of the dosage excreted in the form of the particular group of urinary steroids measured; these were calculated from the differences of the urinary levels on the two days of the experiments, and are based on the total dosage of free steroid administered. The $\mathrm{K} / \mathrm{C}$ ratio rep-

TABLE I

Effect of Substance $S$ on urinary steroid excretion

\begin{tabular}{|c|c|c|c|c|c|c|c|c|c|c|}
\hline \multirow[b]{2}{*}{ Subject } & \multirow[b]{2}{*}{ Age } & \multirow[b]{2}{*}{ Sex } & \multirow[b]{2}{*}{ Compound } & \multirow[b]{2}{*}{ Dose } & \multicolumn{2}{|c|}{ 17-Ketosteroids } & \multicolumn{2}{|c|}{ Corticoids } & \multicolumn{2}{|c|}{ Formaldehydogenic } \\
\hline & & & & & $\mathrm{C}^{*}$ & At & C & A & $\mathrm{C}$ & $A$ \\
\hline & yrs. & & & mg. free & \multicolumn{2}{|c|}{$m g . / d a y$} & \multicolumn{2}{|c|}{$m g . / d a y$} & \multicolumn{2}{|c|}{$m g . / d a y$} \\
\hline $\begin{array}{l}\text { G. W. } \\
\text { S. M. } \\
\text { C. O. } \\
\text { J. W. } \\
\text { H. C. } \\
\text { B. E. } \\
\text { J. C. } \\
\text { A. B. }\end{array}$ & $\begin{array}{c}5 \text { mos. } \\
3 \\
6 \\
8 \\
13 \\
27 \\
28 \\
36\end{array}$ & $\begin{array}{l}M \\
M \\
F \\
F \\
M \\
M \\
F \\
M\end{array}$ & $\begin{array}{l}\quad \text { St } \\
\text { hemi- } \\
\text { succin- } \\
\text { ate, } \\
\text { P.O. }\end{array}$ & $\begin{array}{r}19.4 \\
58.0 \\
77.5 \\
194.0 \\
155.0 \\
233.0 \\
233.0 \\
233.0\end{array}$ & $\begin{array}{l}0.5 \\
0.15 \\
5.77 \\
3.5 \\
1.6 \\
7.0 \\
9.1 \\
9.3\end{array}$ & $\begin{array}{l}0.5 \\
0.85 \\
7.0 \\
6.0 \\
3.7 \\
14.1 \\
15.0 \\
16.9\end{array}$ & $\begin{array}{l}0.43 \\
1.10 \\
4.0 \\
2.68 \\
1.50 \\
4.50 \\
4.00 \\
4.10\end{array}$ & $\begin{array}{c}2.55 \\
7.20 \\
12.2 \\
33.6 \\
21.7 \\
58.8 \\
39.5 \\
56.8\end{array}$ & & \\
\hline $\begin{array}{l}\text { J. Z. } \\
\text { H. Z. } \\
\text { A. F. } \\
\text { R. B. } \\
\text { A. B. } \\
\text { R. E. }\end{array}$ & $\begin{array}{r}4 \\
6 \\
8 \\
22 \\
36 \\
36\end{array}$ & $\begin{array}{l}\mathbf{M} \\
\mathbf{M} \\
\mathbf{F} \\
\mathbf{M} \\
\mathbf{M} \\
\mathbf{M}\end{array}$ & $\begin{array}{l}\quad \mathrm{S} \\
\text { hemi- } \\
\text { succ- } \\
\text { inate, } \\
\text { I.V. }\end{array}$ & $\begin{array}{l}15.6 \\
15.6 \\
19.5 \\
78.0 \\
78.0 \\
78.0\end{array}$ & $\begin{array}{r}0 \\
0.1 \\
1.0 \\
11.7 \\
9.0 \\
9.6\end{array}$ & $\begin{array}{c}0.2 \\
0.35 \\
1.3 \\
16.9 \\
15.3 \\
10.8\end{array}$ & $\begin{array}{l}0.86 \\
2.05 \\
2.90 \\
5.40 \\
5.00 \\
5.18\end{array}$ & $\begin{array}{c}1.70 \\
3.53 \\
4.53 \\
13.9 \\
12.9 \\
11.1\end{array}$ & & \\
\hline $\begin{array}{l}\text { A. S. } \\
\text { J. F. } \\
\text { P. N. } \\
\text { E. O. } \\
\text { A. N. } \\
\text { C. K. } \\
\text { J. C. } \\
\text { B. E. } \\
\text { C. W. } \\
\text { A. B. } \\
\text { R. E. }\end{array}$ & $\begin{array}{r}5 \\
5 \\
9 \\
10 \\
11 \\
24 \\
27 \\
27 \\
28 \\
36 \\
36\end{array}$ & $\begin{array}{l}\text { M } \\
\text { M } \\
\text { F } \\
\text { F } \\
\text { M } \\
\text { M } \\
\text { F } \\
\text { M } \\
\mathbf{M} \\
M \\
M\end{array}$ & \begin{tabular}{l}
\multicolumn{1}{c}{ S } \\
acetate, \\
P.O.
\end{tabular} & $\begin{array}{l}22.5 \\
22.5 \\
58.0 \\
53.5 \\
44.5 \\
89.0 \\
89.0 \\
89.0 \\
89.0 \\
89.0 \\
89.0\end{array}$ & $\begin{array}{c}1.45 \\
0.52 \\
2.90 \\
5.20 \\
4.90 \\
6.50 \\
9.50 \\
12.0 \\
11.0 \\
9.20 \\
8.10\end{array}$ & $\begin{array}{c}1.76 \\
0.67 \\
3.70 \\
6.30 \\
5.90 \\
12.1 \\
13.7 \\
18.0 \\
19.7 \\
15.3 \\
9.70\end{array}$ & $\begin{array}{l}0.26 \\
1.12 \\
2.30 \\
2.85 \\
1.50 \\
6.50 \\
2.30 \\
5.80 \\
8.40 \\
4.90 \\
4.80\end{array}$ & $\begin{array}{c}0.96 \\
1.98 \\
3.90 \\
5.12 \\
3.20 \\
12.1 \\
7.30 \\
13.0 \\
16.9 \\
9.10 \\
7.10\end{array}$ & $\begin{array}{l}4.4 \\
2.0 \\
1.47 \\
2.8 \\
7.0 \\
1.0 \\
5.0 \\
6.4 \\
5.0 \\
4.1 \\
4.8\end{array}$ & $\begin{array}{r}4.4 \\
2.9 \\
2.3 \\
6.9 \\
12.3 \\
16.7 \\
50.0 \\
58.0 \\
50.4 \\
50.4 \\
7.6\end{array}$ \\
\hline $\begin{array}{l}\text { B. E. } \\
\text { C. W. } \\
\text { A. B. }\end{array}$ & $\begin{array}{l}27 \\
28 \\
28\end{array}$ & $\begin{array}{l}\mathbf{M} \\
\mathbf{M} \\
\mathbf{M}\end{array}$ & $\begin{array}{l}\quad \mathrm{F} \& \\
\text { acetate, } \\
\text { P.O. }\end{array}$ & $\begin{array}{l}90.0 \\
90.0 \\
90.0\end{array}$ & $\begin{array}{l}12.0 \\
11.1 \\
10.9\end{array}$ & $\begin{array}{c}11.3 \\
12.0 \\
9.90\end{array}$ & $\begin{array}{l}5.10 \\
8.40 \\
4.70\end{array}$ & $\begin{array}{l}28.5 \\
31.6 \\
17.3\end{array}$ & $\begin{array}{l}2.4 \\
4.8 \\
3.9\end{array}$ & $\begin{array}{l}16.3 \\
20.1 \\
21.6\end{array}$ \\
\hline
\end{tabular}

* Control.

$\dagger$ After compound.

† S, "11-desoxycortisol."

$\$ \mathrm{~F}$, hydrocortisone. 
TABLE II

Per cent of dose excreted in urine

\begin{tabular}{|c|c|c|c|c|c|c|c|c|c|c|c|c|}
\hline & \multicolumn{6}{|c|}{ Children } & \multicolumn{6}{|c|}{ - Adults } \\
\hline & Subject & $\begin{array}{l}\text { Age } \\
\text { yrs. }\end{array}$ & $\begin{array}{l}\text { Keto- } \\
\text { steroids }\end{array}$ & $\begin{array}{l}\text { Corti- } \\
\text { coids }\end{array}$ & $\underset{\text { hydogenic* }}{\text { Formalde- }}$ & $\mathrm{K} / \mathrm{C} \dagger$ & Subject & $\begin{array}{l}\text { Age } \\
\text { yrs. }\end{array}$ & $\begin{array}{l}\text { Keto- } \\
\text { steroids }\end{array}$ & $\begin{array}{l}\text { Corti- } \\
\text { coids }\end{array}$ & $\begin{array}{c}\text { Formalde- } \\
\text { hydogenic }\end{array}$ & $\mathrm{K} / \mathrm{C}$ \\
\hline$A_{+}^{+}$ & $\begin{array}{l}\text { G. W. } \\
\text { S. M. } \\
\text { C. O. } \\
\text { J. W. } \\
\text { H. C. }\end{array}$ & $\begin{array}{r}5 \text { mos. } \\
3 \\
6 \\
8 \\
13\end{array}$ & $\begin{array}{l}0 \\
1.2 \\
1.7 \\
1.3 \\
1.4\end{array}$ & $\begin{array}{l}10.8 \\
10.5 \\
10.5 \\
17.4 \\
14.0\end{array}$ & & $\begin{array}{l}0 \\
0.115 \\
0.160 \\
0.072 \\
0.097\end{array}$ & $\begin{array}{l}\text { B. E. } \\
\text { J. C. } \\
\text { A. B. }\end{array}$ & $\begin{array}{l}27 \\
28 \\
36\end{array}$ & $\begin{array}{l}2.7 \\
2.5 \\
3.2\end{array}$ & $\begin{array}{l}19.9 \\
14.8 \\
22.4\end{array}$ & & $\begin{array}{l}0.135 \\
0.167 \\
0.143\end{array}$ \\
\hline$B \S$ & $\begin{array}{l}\text { J. Z. } \\
\text { H. } \\
\text { A. F. }\end{array}$ & $\begin{array}{l}4 \\
6 \\
8\end{array}$ & $\begin{array}{l}1.0 \\
1.0 \\
1.2\end{array}$ & $\begin{array}{l}5.0 \\
9.5 \\
8.2\end{array}$ & & $\begin{array}{l}0.200 \\
0.105 \\
0.147\end{array}$ & $\begin{array}{l}\text { R. B. } \\
\text { A. B. } \\
\text { R. E. }\end{array}$ & $\begin{array}{l}22 \\
36 \\
36\end{array}$ & $\begin{array}{l}5.2 \\
8.1 \\
1.6\end{array}$ & $\begin{array}{c}10.3 \\
10.1 \\
7.6\end{array}$ & & $\begin{array}{l}0.505 \\
0.802 \\
0.215\end{array}$ \\
\hline $\mathrm{C} \|$ & $\begin{array}{l}\text { A. S. } \\
\text { J. F. } \\
\text { P. N. } \\
\text { E. O. } \\
\text { A. N. }\end{array}$ & $\begin{array}{r}5 \\
5 \\
9 \\
10 \\
11\end{array}$ & $\begin{array}{l}1.3 \\
0.6 \\
1.4 \\
2.1 \\
2.3\end{array}$ & $\begin{array}{l}3.2 \\
3.9 \\
2.7 \\
4.2 \\
3.7\end{array}$ & $\begin{array}{r}0 \\
4.0 \\
1.7 \\
7.7 \\
11.9\end{array}$ & $\begin{array}{l}0.406 \\
0.166 \\
0.518 \\
0.500 \\
0.621\end{array}$ & $\begin{array}{l}\text { C. K. } \\
\text { J. C. } \\
\text { B. E. } \\
\text { C. W. } \\
\text { A. B. } \\
\text { R. E. }\end{array}$ & $\begin{array}{l}24 \\
27 \\
27 \\
28 \\
36 \\
36\end{array}$ & $\begin{array}{l}6.3 \\
4.7 \\
6.9 \\
6.5 \\
6.9 \\
1.8\end{array}$ & $\begin{array}{l}7.4 \\
5.6 \\
8.1 \\
6.4 \\
4.7 \\
2.6\end{array}$ & $\begin{array}{r}17.7 \\
50.0 \\
58.0 \\
34.1 \\
52.0 \\
3.1\end{array}$ & $\begin{array}{l}0.852 \\
0.840 \\
0.852 \\
1.010 \\
1.465 \\
0.692\end{array}$ \\
\hline S & Average & & 1.3 & 8.0 & 5.1 & 0.239 & & & 4.7 & 10.0 & 35.8 & 0.640 \\
\hline F $\mathbb{I}$ & & & & & & & $\begin{array}{l}\text { B. E. } \\
\text { C. W. } \\
\text { A. B. }\end{array}$ & $\begin{array}{l}27 \\
28 \\
36\end{array}$ & $\begin{array}{l}0 \\
1.1 \\
0\end{array}$ & $\begin{array}{l}26.0 \\
25.8 \\
14.2\end{array}$ & $\begin{array}{l}15.6 \\
17.0 \\
18.8\end{array}$ & \\
\hline
\end{tabular}

* Formaldehydogenic steroids (nonketonic).

† Ratio of per cent ketosteroids to per cent corticoids.

$\ddagger S$ hemisuccinate P.O. ( $\mathrm{S}$ is "11-desoxycortisol").

$\$$ S hemisuccinate I.V.

S acetate P.O.

१ Hydrocortisone acetate P.O.

resents the relationship of the percentage dose converted to 17 -ketosteroids over corticoids.

\section{7-Ketosteroids}

The rise in excretion of 17 -ketosteroids, released by glucuronidase, was greater in the adults, particularly when the hemisuccinate of the steroid was given by vein, or the acetate given orally. In all experiments the adults demonstrated a greater conversion of Substance $S$ to urinary 17ketosteroids. A single exception among the adults, Subject R. E., exhibited less conversion than his age peers after intravenous hemisuccinate or oral acetate. His excretion of other steroid metabolites was also unique, as will be shown below. The difference between adults and children, in the increment of 17-ketosteroids, even when expressed as $K / C$ ratio, was statistically significant $(p=0.001)$. As stated below, there are differences depending upon the form of Substance S; general averages are shown in Table II for statistical purposes only.

It has been previously demonstrated that the major 17-ketosteroid excreted after the admini- stration of Substance $\mathrm{S}$ is etiocholanolone (2). Two collections of urine (Subjects A. B. and B. E., after the oral administration of the acetate) were pooled, and the total amount, minus the small aliquots employed for other tests, was hydrolyzed with beta-glucuronidase. After Girard separation, the residue was chromatographed on alumina for the resolution of the 17-ketosteroids. The total amount of 17-ketosteroids recovered from the column, as measured by the Zimmermann reaction on all fractions, was $21.9 \mathrm{mg}$. A single compound accounted for $11.9 \mathrm{mg}$. This proved to be etiocholanolone by infrared spectroscopy. The total quantity of etiocholanolone isolated from these two specimens agrees well with the total rise in 17-ketosteroids during the experiment, indicating that this compound accounts almost entirely for the increase; this also reveals that Substance $S$ does not significantly suppress the 17-ketosteroids in urine.

Three experiments, in which adult subjects were given hydrocortisone acetate by mouth, are included in Table I for comparison. A rise of 17- 
ketosteroid excretion was not noted, although this does not imply a failure of conversion to 17 -ketosteroids. The extent of the conversion is partially obscured by the suppressive effect of hydrocortisone on endogenous 17 -ketosteroid production.

The levels of 17 -ketosteroids measurable after acid hydrolysis were approximately 10 per cent higher than after glucuronidase hydrolysis in all cases, and are not included in the tables.

\section{Corticoids}

The corticoids measured in the urine by the Porter-Silber reaction presumably represent 17,21dihydroxy-20-ketosteroids. The greatest increment in corticoid excretion followed the administration of the hemisuccinate of Substance S. The rise following administration of the acetate of Substance $\mathrm{S}$ was considerably less than that after hydrocortisone acetate. Differences between adults and children in the excretion of corticoids were apparent, but these were relatively less than in the case of the 17-ketosteroids, as expressed in the $\mathrm{K} / \mathrm{C}$ ratio in Table II.

The raised levels of urinary corticoids following the administration of Substance $S$ were shown to reflect excretion of the reduced metabolite of this steroid, namely pregnane-3 $\alpha, 17 \alpha, 21$-triol-20-one ("tetrahydro S"). The total remaining volumes of urine from Subjects B. E. and A. B., after the oral administration of Substance $S$ hemisuccinate, were hydrolyzed with beta-glucuronidase as outlined above. Column chromatography of the steroids by the method of Katzenellenbogen, Dobriner, and Kritchevsky (10) yielded two major fractions. The first was eluted with 3 to 4 per cent ethanol in methylene chloride and weighed $130 \mathrm{mg}$. This residue, after crystallization from methanol, melted at 186 to $187^{\circ} \mathrm{C}$. and after acetylation, at 202 to $203^{\circ} \mathrm{C}$. The acetylated compound was submitted to infrared examination, through the kindness of Doctor Thomas Gallagher, and was found to be identical with the diacetate of pregnane- $3 \alpha, 17 \alpha, 21$ triol-20-one ("tetrahydro S"). The second major fraction eluted is described below.

\section{Formaldehydogenic steroids}

The measurement of formaldehydogenic nonketonic steroids after the oral administration of $\mathrm{S}$ acetate was used as an index of the total reduc- tion of Substance $S$ to pregnane- $3 \alpha, 17 \alpha, 20 \xi, 21$ tetrol. Such metabolites of related C-21 steroids have been found in urine in significant amounts by Fukushima, Leeds, Bradlow, Kritchevsky, Stokem, and Gallagher (13). It is apparent that adults excrete greater quantities of this type metabolite after the administration of Substance $S$ than after a dose of hydrocortisone. The conversion to the tetrol is greater in the adult than the child, after the administration of $\mathrm{S}$ acetate by mouth. Subject R. E., the adult who demonstrated a relatively low conversion of Substance $S$ to 17 -ketosteroids, also excreted smaller quantities of the C-20-reduced derivative.

Since such large quantities of the completely reduced derivative of Substance $S$ were apparently excreted, as indicated by the formaldehydogenic method, the urine pools described under "Corticoids" were re-examined. During chromatography on silica, a large crystalline residue was obtained following elution with 6 per cent ethanol in methylene chloride. This material failed to give the blue tetrazolium or Porter-Silber reactions. The melting point of the free compound was 246 to $251^{\circ} \mathrm{C}$., and after acetylation, 144 to $146^{\circ} \mathrm{C}$. These properties were identical with those of a substance previously and tentatively identified by the present authors (14) as pregnane- $3 \alpha, 17 \alpha, 20 \xi$, 21-tetrol. Doctor Thomas Gallagher reported that by infrared examination this compound was virtually identical to $\mathrm{P} 666$, the material previously submitted.

\section{DISCUSSION}

These studies indicate that there are differences between the immature and adult human subject with respect to the metabolism of Substance S. In adults, there is a greater conversion of Substance $\mathrm{S}$ to 17 -ketosteroids and metabolites reduced at C-20. It may be speculated that those systems responsible for the degradation or reduction of the side-chain are more efficient with the attainment of maturity; this would include many factors, such as hepatic flow and size, enzymes, cofactors and so forth. Further studies are in progress to determine whether similar differences exist in the metabolism of C-21 steroids other than Substance S. Furthermore, in spite of the differences shown in the metabolism of Substance $S$ between children and adults, there is no evidence that 
this steroid is normally released by the adrenal gland. Hence it cannot be specifically implied that this compound plays a definite role in the increase of 17-ketosteroids with increasing age. It is suggested that other similar precursors are responsible, and Substance $S$ has been employed only as a model in these experiments.

The greater conversion of Substance $S$ to 17ketosteroids in adults suggests another explanation for the increased urinary excretion of 17 ketosteroids at adolescence. The greater facility with which the degradation of Substance S occurred in the older subjects indicates that, in some portion, the elevated 17-ketosteroids arise from C-21 precursors, although the latter compounds are not themselves produced in significantly greater amounts when related to the body surface area (1).

Although the excretion of corticoids has also been shown to be somewhat less in children, after the administration of the test compounds, the $\mathrm{K} / \mathrm{C}$ ratio (Table II) clearly indicates that the differences in the 17-ketosteroids are considerably and significantly greater. One child (C. O., S hemisuccinate by mouth) revealed a ratio of 17 ketosteroids to corticoids similar to the adult. It is interesting that this subject was clinically more advanced than her years and her baseline excretion of 17-ketosteroids (5.7 mg. per day, Table I) was already approaching adolescent levels. Contrariwise, one adult (B. E.) consistently failed to show the degree of conversion to 17 -ketosteroids or the reduction at C-20 noted in the other adults. This was regarded as a "normal variant," since the subject was in good health and the observation of such individuality in steroidal metabolism among normal subjects is not without precedent (15).

The major urinary products isolated after the administration of Substance $S$ in these experiments included: etiocholanolone, tetrahydro-S and pregnane-3 $\alpha, 17 \alpha, 20 \xi, 21$-tetrol. Differences in results are noted between the various forms of Substance $\mathrm{S}$ and the route of administration. It has been reported by others (2) that the excretion of etiocholanolone is greatest after the oral administration of the acetate of Substance S. The data presented in three instances, for purposes of comparison, after the administration of hydrocortisone to adults are in agreement with other studies $(16,17)$. The excretion of 17 -ketosteroids after the use of hydrocortisone does not lend itself to interpretation in these experiments. The precise identification of urinary 17 -ketosteroids is required in order to arrive at the extent of conversion, when employing steroids which suppress endogenous adrenocortical function. However, there are larger amounts of urinary metabolites, reduced at C-20, after the administration of Substance $\mathrm{S}$ than with hydrocortisone. The recovery of cortol and cortolone, both highly water soluble, has not been checked; hence the difference may be artifactual. However, the order of the quantity measured as nonketonic formaldehydogenic steroids (Tables I and II) is reasonably close to that reported by isotopic techniques (13) ; and the inverse reciprocal relationships of the ketonic corticoids to the nonketonic steroids, between Substance $\mathrm{S}$ and Compound $\mathrm{F}$ reported here, are in keeping with a true difference in metabolism. Perhaps the presence of an oxygen function at C-11 handicaps the reduction at C-20 by biological systems.

The detailed chromatographic studies of some pools of urine in these experiments, in which three major metabolites of Substance $S$ have been isolated and identified, show good agreement with the results indicated by standard routine analyses.

In a few subjects receiving Substance $\mathrm{S}$ hemisuccinate by mouth, fractional urine collections were obtained, for 8 and 16 hours after the dose. Sixty-five per cent of the total daily amount of 17 -ketosteroids and corticoids was present in the first 8 hours. The investigations were not continued beyond 24 hours and the results do not indicate the total recoverable metabolites over several days. Therefore, the interpretation of differences is limited to the single 24 hour period, and the possibility that relatively larger quantities of metabolites might appear in the younger subjects over a prolonged period is unanswered. However, even if this were the case, significant differences in rates of metabolism would obtain during the first day.

\section{SUMMARY}

The administration of Substance S (11-desoxycortisol) to a group of human subjects revealed differences in the metabolism between adults and children. In mature subjects there was a greater 
conversion of Substance $\mathrm{S}$ to 17-ketosteroids. The increment was shown to be primarily due to a rise in the urinary excretion of etiocholanolone. This suggests another mechanism for the rise in the urinary excretion of 17 -ketosteroids at adolescence, apart from direct genesis of gonadal or adrenal C-19 steroids per se. In addition, the adults produced greater quantities of urinary metabolites reduced at C-20. It also appears that Substance $\mathrm{S}$ is more readily reduced at C-20 than hydrocortisone. Tetrahydro-S has been isolated and identified in the urine after the administration of Substance S ; another compound has been isolated and tentatively identified as pregnane $3 \alpha, 17 \alpha$,

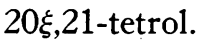

\section{ACKNOWLEDGMENT}

The infrared identifications were procured through the kindness of Doctors T. F. Gallagher, S. Solomon and S. Lieberman. The Upjohn Company generously supplied the steroids employed in these studies.

\section{REFERENCES}

1. Talbot, N. B., Zygmuntowicz, A. S., Wood, M., and Christo, E. Observations on adrenal cortical "sugar-fat-nitrogen" hormone ("11-17-OCS") and "17-ketosteroid precursor" production by normal and abnormal individuals of various ages in Proc. First Clinical ACTH Conference, J. R. Mote, Ed. Philadelphia, Blakiston \& Co., 1950, p. 32.

2. Birke, G. The effect of Reichstein's Substance $S$ on the excretion of 17-ketosteroids. Acta endocr. (Kbh.) 1954, 15; 17.

3. Bongiovanni, A. M. A method adapted for the determination of urinary 17 -ketosteroids in children. J. Pediat. 1951, 39, 606.

4. Bongiovanni, A. M., Eberlein, W. R., and Thomas, P. Z. Use of an organic base in the Zimmermann reaction. J. clin. Endocr. 1957, 17, 331.

5. Wilson, $H$. Chromogenic values of various ketosteroids in a micro modification of the Zimmermann reaction. Arch. Biochem. 1954, 52, 217.
6. Silber, R. H., and Porter, C. C. Determination of 17,21-dihydroxy-20-ketosteroids in urine and plasma in Methods of Biochemical Analysis, D. Glick, Ed. New York, Interscience Publishers, Inc., 1957, vol. 4, p. 139.

7. Bongiovanni, A. M., and Eberlein, W. R. Critical analysis of methods for measurement of pregnane3-alpha, 17-alpha, 20-alpha-triol in human urine. Analyt. Chem. 1958, 30, 388.

8. Schneider, J. J. Further isolation of adrenocortical compounds from male urine. J. biol. Chem. 1952, 194, 337.

9. Bongiovanni, A. M., and Eberlein, W. R. A microformaldehydogenic method for analysis of chromatographic fractions of adrenal steroids. J. Lab. clin. Med. 1956, 48, 320.

10. Katzenellenbogen, E. R., Dobriner, K., and Kritchevsky, T. H. Separation of steroid hormones and their metabolites by partition type chromatography. J. biol. Chem. 1954, 207, 315.

11. Lakshmanan, T. K., and Lieberman, S. An improved method of gradient elution chromatography and its application to the separation of urinary ketosteroids. Arch. Biochem. 1954, 53, 258.

12. Pincus, G., and Pearlman, W. H. Fractionation of neutral urinary steroids. Endocrinology 1941, 29, 413.

13. Fukushima, D. K., Leeds, N. S., Bradlow, H. L., Kritchevsky, T. H., Stokem, M. B., and Gallagher, T. F. The characterization of four new metabolites of adrenocortical hormones. J. biol. Chem. 1955, 212, 449.

14. Eberlein, W. R., and Bongiovanni, A. M. Plasma and urinary corticosteroids in the hypertensive form of congenital adrenal hyperplasia. J. biol. Chem. 1956, 223, 85.

15. Dobriner, K. Studies in steroid metabolism. XIX. The alpha-ketosteroid excretion pattern in normal males. J. clin. Invest. 1953, 32, 940.

16. Brown, H., Willardson, D. G., Samuels, L. T., and Tyler, F. H. 17-Hydroxycorticosteroid metabolism in liver disease. J. clin. Invest. 1954, 33, 1524.

17. Peterson, R. E., Pierce, C. E., Wyngaarden, J. B., Bunim, J. J., and Brodie, B. B. The physiological disposition and metabolic fate of cortisone in man. J. clin. Invest. 1957, 36, 1301.

\section{SPECIAL NOTICE TO SUBSCRIBERS}

Post Offices will no longer forward the Journal when you move.

Please notify The Journal of Clinical Investigation, Business Office, 333 Cedar Street, New Haven 11, Conn., at once when you have a change of address, and do not omit the zone number if there is one. 